\title{
Thromboelastometry Based Early Goal-Directed Coagulation Management Reduces Blood Transfusion Requirements, Adverse Events, and Costs in Acute Type A Aortic Dissection: A Pilot Study
}

\author{
Alexander A. Hanke ${ }^{a}$ \\ Klaus Görlinger ${ }^{c}$ \\ a Department of Anesthesiology and Intensive Care Medicine, Hanover Medical School, \\ ${ }^{\mathrm{b}}$ Department of Cardiovascular Surgery, German Heart Center Munich, \\ ${ }^{c}$ Department of Anesthesiology and Intensive Care Medicine, \\ ${ }^{d}$ Department of Thoracic and Cardiovascular Surgery, University Hospital Essen, Germany
}

\section{Keywords}

Allogeneic transfusion - Anesthesia - Blood products .

Cardiac surgery $\cdot$ Coagulation factors .

Massive transfusion - Perioperative period · Point of care

\section{Summary}

Background: In aortic surgery bleeding complications can be fatal. Therefore, rotational thromboelastometry(ROTEM $\left.{ }^{\mathrm{TM}}\right)$ based coagulation management was introduced. Methods: After 5 cases of acute type A aortic dissection and aortic arch replacement had been treated based on ROTEM findings (ROTEM group; RG), 5 cases without ROTEM were matched as control group (CG). CG treatment was based on conventional tests and clinical findings. Blood component and coagulation factor requirements, ventilation time, duration of stay at intensive care unit (ICU), hospitalization, and thrombotic or bleeding incidents as well as transfusion-associated costs were compared. Results: Administration of blood products and coagulation factor concentrates, ventilation time, ICU length of stay, and hospitalization tended to be lower in RG. Postoperative plasma transfusion $(p=0.038)$, recognized incidents $(p=0.048)$, and resulting costs on coagulation treatment ( $p=0.049$ ) were significantly reduced. Conclusion: Our data suggest that ROTEM-based coagulation management can reduce transfusion requirements and corresponding costs in patients with aortic arch replacement. These data has to be confirmed by prospective randomized trials.

\author{
Schlüsselwörter \\ Allogene Transfusion - Anästhesie · Blutprodukte . \\ Herzchirurgie - Gerinnungsfaktoren . \\ Massivtransfusion - Perioperative Periode - "Point of care»
}

\section{Zusammenfassung}

Hintergrund: Blutungskomplikationen in der Aortenchirurgie gehen mit erheblichen Risiken für die Patienten einher und können fatale Folgen haben. Aus diesem Grund wurde ein Rotationsthromboelastometrie(ROTEM $\left.{ }^{\mathrm{TM}}\right)$-basierter Algorithmus zum Gerinnungsmanagement eingeführt. Methoden: Nach 5 Fällen von Patienten mit akuter Typ-A-Aorten-Dissektion und entsprechendem Aortenbogenersatz, welche gemäß dem genannten Algorithmus therapiert wurden (ROTEMGruppe; RG), wurden 5 Fälle ohne ROTEM-Monitoring als Kontrollgruppe (CG) genutzt. Die Therapie der CG basierte auf konventionellen Labortests und klinischen Eindrücken. Der Verbrauch von Blutkomponenten und Gerinnungsfaktorkonzentraten, Ventilations- und Liegezeiten auf der Intensivstation wie auch die Dauer des Intensivaufenthalts und der Hospitalisierung wurden erfasst. Ferner wurden thrombembolische und Blutungskomplikationen sowie die transfusionsassoziierten Kosten analysiert. Ergebnisse: Der Verbrauch von Blutprodukten und Gerinnungsfaktorkonzentraten, die Beatmungsdauer, die Intensivliegedauer sowie die Hospitalisierung waren tendenziell niedriger in der RG. Der postoperative Verbrauch an gefrorenem Frischplasma ( $p=0,038)$, die Komplikationshäufigkeit $(p=0,048)$ und die transfusionsassoziierten Kosten $(p=0,049)$ waren in der RG signifikant reduziert. Schlussfolgerung: Unsere Daten deuten darauf hin, dass durch ein ROTEM-basiertes Gerinnungsmanagement der Bedarf an Transfusionen und die entsprechend assoziierten Kosten bei Patienten mit akuter Typ-ADissektionen reduziert werden können. Dies muss künftig durch prospektive randomisierte Studien belegt werden.

\section{KARGER \\ Fax +497614520714 \\ Information@Karger.de}

www.karger.com (c) 2012 S. Karger GmbH, Freiburg

$660-3796 / 12 / 0392-0121 \$ 38.00 / 0$

Accessible online at:

www.karger.com/tm
Dr. med. Alexander A. Hanke

Department of Anesthesiology and Intensive Care Medicine; OE 80.50 Hanover Medical School

Carl-Neuberg-Straße 1, 30625 Hannover, Germany

hanke.alexander@mh-hannover.de 


\section{Introduction}

Surgery of the aortic arch is complex, and bleeding complications are still within the leading causes of death [1-6]. Furthermore, blood transfusion is associated with increased morbidity and mortality [7-12]. Therefore, in 2005 we implemented a rotational thromboelastometry(ROTEM $\left.{ }^{\mathrm{TM}}\right)$-based point-of-care coagulation management algorithm in cardiovascular surgery [13-15]. ROTEM assesses whole blood coagulation by analyzing clot stability over time. This viscoelastic method is much less sensitive against agitation compared to conventional thrombelastography and provides results within 10-15 min which enables a calculated goal-directed first- line therapy with hemostatic drugs and specific coagulation factor concentrates such as fibrinogen concentrate or prothrombin complex concentrate (PCC) [16-24].

The aim of our pilot study was to review the first 5 patients undergoing aortic arch replacement after acute type A dissection with ROTEM-based coagulation management and compare them to a matched control group with standard treatment performed in the same period in order to evaluate the effectiveness of our point-of-care coagulation management algorithm regarding to transfusion requirements, transfusion- and coagulation factor concentrates-related costs, incidence of massive transfusion, bleeding and thrombotic/ thromboembolic adverse events as well as postoperative ventilation time, duration of stay at intensive care unit (ICU), hospitalization time, and mortality.

\section{Material and Methods}

The study was approved by the Institutional Ethic Committee (University Hospital Essen, Germany) and performed at the Department of Thoracic and Cardiovascular Surgery of University Hospital Essen, Germany. The first 5 patients with acute type A aortic dissection and aortic arch replacement treated due to findings in thromboelastometry (ROTEM group; RG) were included in this pilot study (from October 2005 to January 2007). Then 5 patients without ROTEM monitoring operated in the same time period (from September 2005 to February 2007) were matched according to sex, age, and cardiopulmonary bypass (CPB) time as a control group (CG) and the clinical courses were compared to those of the RG.

\section{Anesthesia Management}

Anesthesia in patients of both groups was performed according to the hospital's standard procedure. Induction was conducted with $0.3 \mathrm{mg} / \mathrm{kg}$ of etomidate, $0.5 \mu \mathrm{g} / \mathrm{kg}$ of sufentanil and $0.5 \mathrm{mg} / \mathrm{kg}$ of rocuronium bromide. During induction of anesthesia, fluid therapy was maintained by $500 \mathrm{ml}$ of Ringer's solution. For maintenance of anesthesia, isoflurane was titrated to an end tidal concentration of $0.8-1.2 \%$ until completion of cardiopulmonary bypass (CPB). Additional boluses of sufentanil were applied for pain therapy. For constitution of $\mathrm{CPB}$, anticoagulation was induced by a bolus of $400 \mathrm{IU} / \mathrm{kg}$ of heparin to achieve an activated clotting time (ACT) of more than $400 \mathrm{~s}$. Additional injections of 50-100 IU heparin per kg body weight were given as needed based on ACT results (as measured by Hemochron Jr. Signature; ITC, Edison, NY, USA). All patients received aprotinin in a dosage of $2 \times 10^{6} \mathrm{KIU}$ (Trasylol $^{\mathrm{TM}}$; Bayer AG, Leverkusen, Germany). During CPB operation, isoflurane was applied directly to the
CPB. For reversal of anticoagulation after weaning from CPB $3 \mathrm{mg} / \mathrm{kg}$ protamine (Protamin ME 1000 I.E./ml, MEDA Pharma, Bad Homburg, Germany; $10 \mathrm{mg}$ protamine hydrochloride corresponding to 1,000 heparin antidote units) were administered. Further protamine injections of up to an overall dose of $4 \mathrm{mg} / \mathrm{kg}$ body weight were given, if necessary.

\section{Coagulation and Transfusion Management}

Coagulation management in the CG most likely was dependent on the anesthetist's experience. Beside the 'view at the operation field', the following laboratory parameters were accessible amongst others on demand: blood cell count (including hemoglobin concentration and platelet count), activated partial thromboplastin time (aPTT), international normalized ratio (INR), and fibrinogen concentration. ACT and blood gas analysis (including hemoglobin and ionized calcium concentration) were available directly in the operating room. There was no strict standard protocol for coagulation management in the control group but the indication for a hemostatic intervention was based on the presence of diffuse bleeding after heparin -reversal by protamine after weaning from CPB. Packed RBC transfusion was targeted to a hemoglobin level of $9 \mathrm{~g} / \mathrm{dl}$. For hemostatic therapy the anesthetists in both groups had the options to administer fresh frozen plasma (FFP), pooled platelet concentrates (PCs) as well as coagulation factor concentrates which included fibrinogen concentrate (Haemocomplettan P ${ }^{\mathrm{TM}}$; CSL Behring GmbH, Marburg, Germany), prothrombin complex concentrate (PCC) (Beriplex P/N ${ }^{\mathrm{TM}}$; CSL Behring $\mathrm{GmbH}$ ), antithrombin concentrate (Kybernin P ${ }^{\mathrm{TM}}$; CSL Behring $\mathrm{GmbH}$ ), factor XIII concentrate (Fibrogammin P ${ }^{\mathrm{TM}}$; CSL Behring $\mathrm{GmbH}$ ), and activated recombinant factor VII (NovoSeven ${ }^{\mathrm{TM}}$; Novo Nordisk A/S, Bagværd, Denmark). According to a common practice at this time, antithrombin concentrate administration was linked to PCC treatment in a ratio of $1: 1$ in the $C G$ in order to avoid thromboembolic events.

In the RG, coagulation management was guided by a coagulation management algorithm (fig. 1) based on ROTEM analysis (ROTEM ${ }^{\mathrm{TM}}$; TEM International GmbH, Munich, Germany). Key point is a thromboelastometric evaluation of citrated whole blood after declamping of the aorta and before weaning from CPB under complete anticoagulation with heparin. Therefore, tests with addition of a heparin inhibitor (EXTEM ${ }^{\mathrm{TM}}$ or FIBTEM ${ }^{\mathrm{TM}}$ ) or heparinase $\left(\right.$ HEPTEM $^{\mathrm{TM}}$ ) were used to anticipate necessary coagulation treatment after weaning from CPB. Hemoglobin concentration was targeted to $9 \mathrm{~g} / \mathrm{dl}$, too, and hemostatic interventions were performed only in the presence of diffuse bleeding after heparin reversal by protamine. Coagulation management was performed according to an algorithm (fig. 1) that included the following steps. Comparison of coagulation times (CT) in intrinsically activated tests with and without addition of heparinase (HEPTEM and INTEM) for detection or exclusion of residual heparin effects. If residual heparin effects were verified, further protamine was administered as described before. Fibrinogen concentrate was administered in case of maximum clot firmness (MCF) in FIBTEM below $16 \mathrm{~mm}$. PCs were administered in case of CT in EXTEM longer than $90 \mathrm{~s}$. Administration of antithrombin concentrate was not linked to PC treatment in the RG. PCs were transfused if MCF in EXTEM was below $50 \mathrm{~mm}$ and fibrinogen deficiency and fibrin polymerization disorders could be excluded by a MCF in FIBTEM of at least $16 \mathrm{~mm}$. FFP was transfused if CT in INTEM and HEPTEM was longer than $240 \mathrm{~s}$. Further details of the principles of our ROTEM-based coagulation management have been described elsewhere $[13,15,17,19]$. In presence of ongoing diffuse bleeding after performing the above mentioned steps and exclusion of surgical bleeding, administration of desmopressin (DDAVP), coagulation factor XIII concentrate or activated recombinant factor VII (rFVIIa) could be considered by the anesthetist.

\section{Surgical Management}

In all patients a one-stage repair via a midline sternotomy was performed. An industrially manufactured standardized and CE-marked hybrid stent graft (E-vita Open; Jotec, Hechingen, Germany) especially made for an- 
tegrade open stent grafting of the descending aorta was used. This device consists of a stent graft with an integrated Dacron vascular prosthesis enabling for direct and continuous aortic arch replacement after stent grafting of the descending aorta. Further details of the surgical technique have been described elsewhere [25]. In all cases, the underlying pathology within the thoracic aspect of the aorta could be excluded in a one-stage approach, and thrombosis of the false lumen was detectable by transesophageal echocardiography already at the end of surgery.

\section{Matching and Postoperative Treatment}

Five patients without ROTEM monitoring (CG) operated in the same time period were matched by sex, age, and CPB time. CG treatment was based on conventional laboratory tests and clinical findings. Postoperative treatment was at the intensive care unit (ICU) specialist's discretion; conventional approaches were used in both groups according to the clinical standard procedures.

\section{Recognized Parameters and Statistics}

The following clinical parameters were recognized and compared: ROTEM parameters in RG, allogeneic blood products and coagulation factor concentrate requirement during surgery and within the first $24 \mathrm{~h}$ at ICU and their corresponding costs, conventional coagulation parameters at ICU admission after surgery (INR, aPTT, fibrinogen level, platelet count, hemoglobin), incidence of massive transfusion $(\geq 10$ units of RBCs), bleeding and thrombotic/thromboembolic incidents as identified clinically or by computed tomography angiography, postoperative ventilation time, duration of stay at ICU, hospitalization time, and in-hospital and 6-month mortality.

For statistical analysis of the data two-tailed t-tests were performed. For recognized incidents Fischer's exact test for contingency tables was performed. The Statistical Package for Social Sciences (SPSS for Windows, 13.0, SPSS Inc., Chicago, IL, USA) and GraphPad Prism (Version 4.02, GraphPad Software Inc., San Diego, CA, USA) were used. A p value below 0.05 was considered to be significant. Values are presented as means (ranges), means \pm standard deviation (SD), or numbers $(\%)$, as appropriate.

\section{Results}

Five patients were treated according to results of the ROTEM analysis, and 5 patients, matched by sex, age and CPB time, were treated conventionally (4 male and 1 female patient in both groups; mean age \pm SD (range): $59 \pm$ 13 years (45-76 years) in RG vs. 58 years \pm 16 years $(42-81$ years) in CG; mean CPB time $\pm \mathrm{SD}$ (range) was 3:49 \pm 0:15 $\mathrm{h}(3: 35-4: 16 \mathrm{~h})$ in the RG and 3:19 $\pm 0: 53 \mathrm{~h}(2: 18-4: 23 \mathrm{~h})$ in the $\mathrm{CG}$.

Fig. 1. Algorithm for point-of-care coagulation management in patients with acute type A aortic dissection based on results of rotational thromboelastometry (ROTEM). ROTEM parameter: $\mathrm{CT}=$ clotting time; $\mathrm{MCF}=$ maximum clot firmness. ROTEM Assays: $\mathrm{EX}=\mathrm{EXTEM} ;$ FIB = FIBTEM; IN = INTEM; HEP = HEPTEM. Other abbreviations: $\mathrm{Ca}$ = ionized calcium; $\mathrm{CPB}=$ cardiopulmonary bypass; $\mathrm{DDAVP}=$ desmopressin; FXIII = factor XIII concentrate; FFP = fresh frozen plasma; $\mathrm{Hb}=$ hemoglobin; $\mathrm{PCC}=$ prothrombin complex concentrate; PRBC $=$ packed red blood cells; rFVIIa = activated recombinant factor VII; Tc $=$ core temperature.

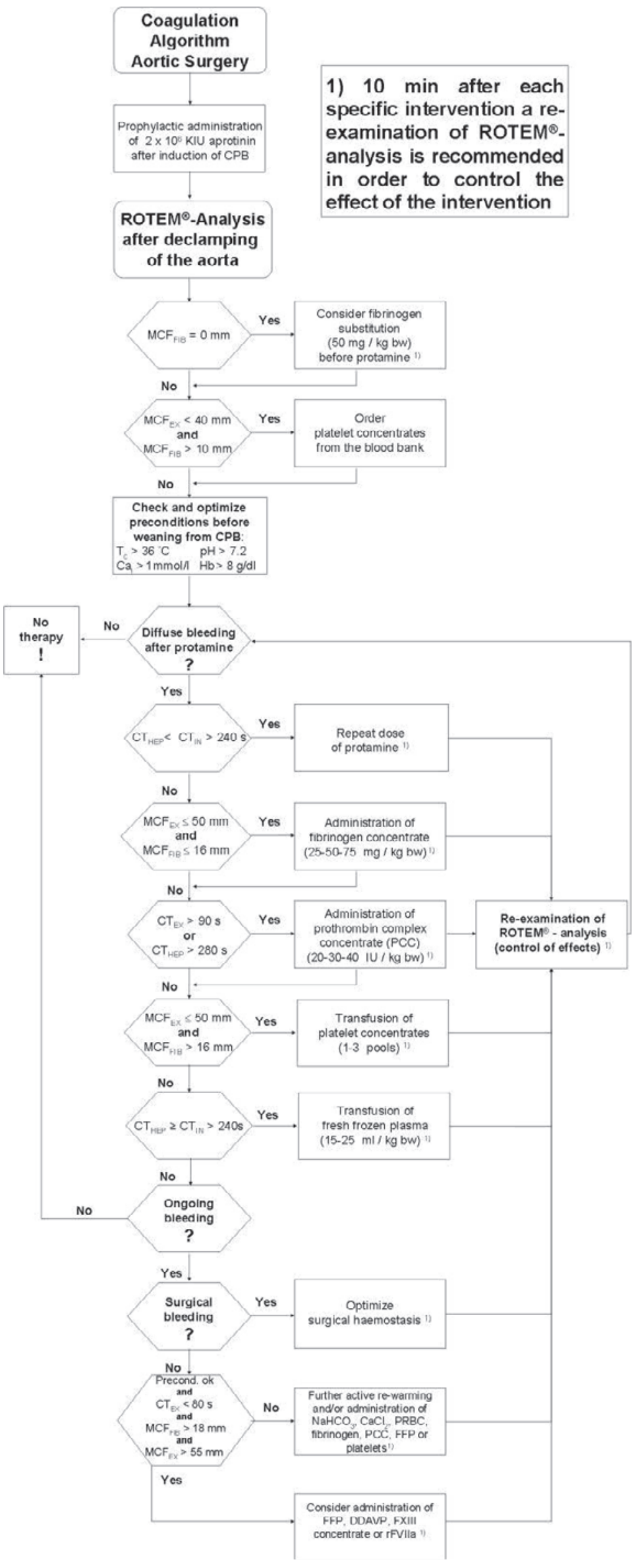

Transfus Med Hemother 2012;39:121-128 
Fig. 2. Requirements for allogeneic blood products and coagulation factor concentrates during surgery: In the ROTEM group (white bars) less packed red blood cells (RBC), fresh frozen plasma (FFP), fibrinogen concentrate, prothrombin complex concentrate (PCC), and antithrombin concentrate (ATIII) were used as compared to control group (grey bars). None of these reductions achieved statistical significance during surgery alone. $\mathrm{PC}=$ platelet concentrates.

Fig. 3. Requirements for allogeneic blood products and coagulation factor concentrates during the first 24 postoperative $h$ at ICU: In the ROTEM group (white bars) less packed red blood cells (RBC) and fresh frozen plasma (FFP) were transfused, but only the reduction in FFP transfusion achieved statistical significance $(\mathrm{p}=0.038) . P C=$ platelet concentrates, $\mathrm{PCC}=$ prothrombin complex concentrate, ATIII $=$ antithrombin concentrate .

Fig. 4. Requirements for allogeneic blood products and coagulation factor concentrates during the whole study period ( during surgery ROTEM group (white bars) less packed red blood cells (RBC), fresh frozen plasma (FFP), fibrinogen concentrate, prothrombin complex concentrate (PCC), and antithrombin concentrate (ATIII) was used. Only reduction of FFP transfusion and ATIII administration achieved statistically significance in this pilot study. $\mathrm{PC}=$ platelet concentrate. and the first 24 postoperative $h$ at ICU): In the
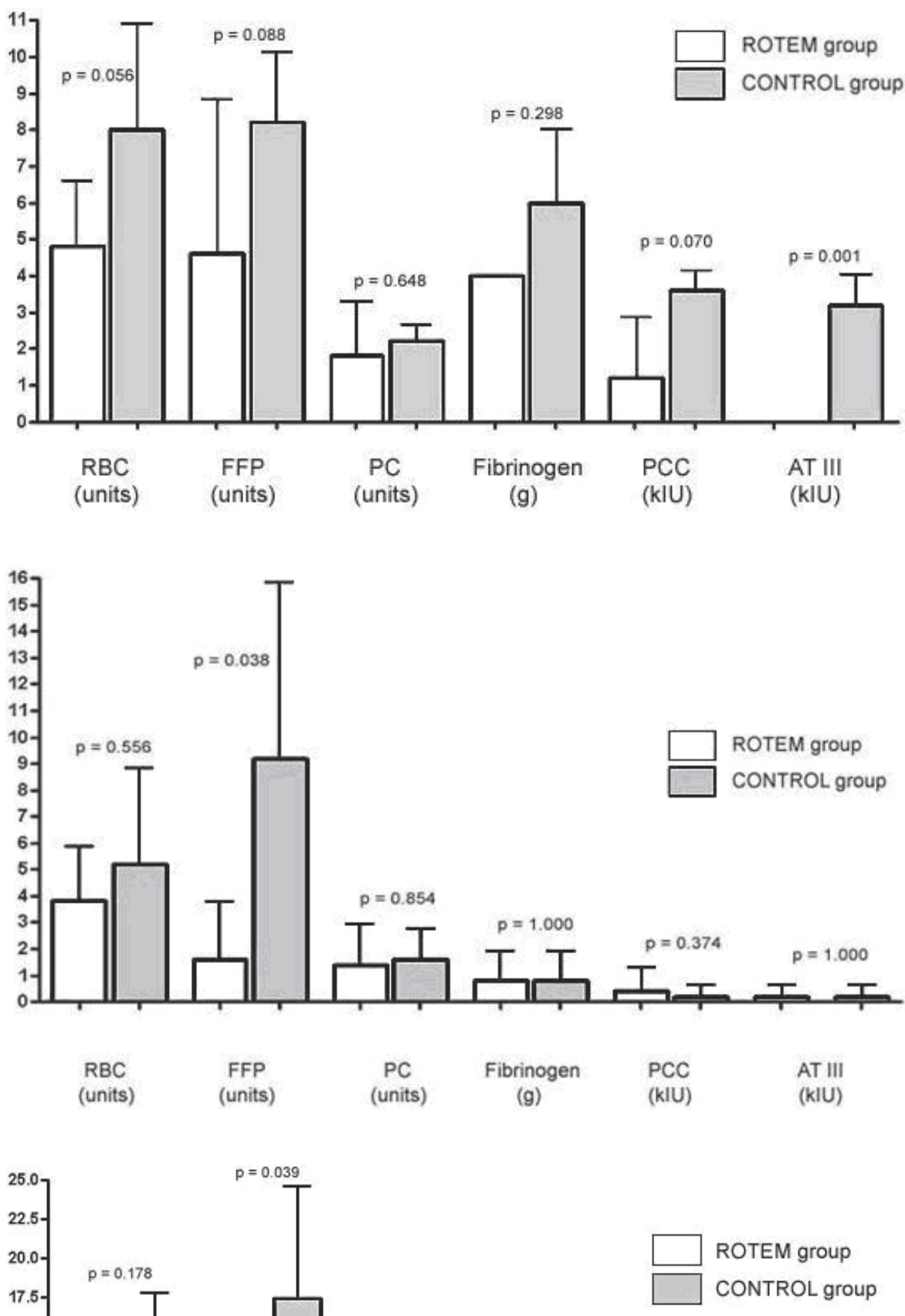

Requirements of allogeneic blood products and coagulation factor concentrates during surgery, during the first $24 \mathrm{~h}$ after admission at ICU, and during surgery and the first $24 \mathrm{~h}$ at ICU together are displayed in figures 2-4.
Transfusion requirements during surgery were insignificantly reduced in RG (fig. 2); this reduction was most pronounced for RBCs $(4.8 \pm 1.8$ units in RG vs. $8.0 \pm 2.9$ units in $\mathrm{CG} ; \mathrm{p}=0.056), \mathrm{FFP}(4.6 \pm 4.2$ units in RG vs. $8.2 \pm 1.9$ units in 
Table 1. Conventional laboratory parameters before and after surgery ${ }^{\mathrm{a}}$

\begin{tabular}{|c|c|c|c|c|c|c|c|}
\hline & $\begin{array}{l}\text { ROTEM group } \\
\text { before surgery }\end{array}$ & $\begin{array}{l}\text { Control } \\
\text { before surgery }\end{array}$ & $\mathrm{p}$ & $\begin{array}{l}\text { ROTEM group } \\
\text { after surgery }\end{array}$ & $\begin{array}{l}\text { Control } \\
\text { after surgery }\end{array}$ & $\mathrm{p}$ & Normal range \\
\hline Hemoglobin, g/dl & $13.6(9.2-16.2)$ & $14.3(13.3-16.7)$ & 0.595 & $9.3(8.1-10.4)$ & $9.3(6.9-11.0)$ & 0.9 & $\begin{array}{l}\text { male } 13.7-17.2 \\
\text { female } 12.0-15.2\end{array}$ \\
\hline Platelet count $\times 1,000 / \mu \mathrm{l}$ & $145.6(96-205)$ & $179.3(149-212)$ & 0.251 & $96.2(70-122)$ & $112.8(67-153)$ & 0.571 & $\begin{array}{l}\text { male } 140-320 \\
\text { female } 180-380\end{array}$ \\
\hline aPTT, s & $29.8(23.0-44.7)$ & $27.0(22.9-29.0)$ & 0.507 & $49.7(37.1-75.8)$ & $50.4(47.7-54.5)$ & 0.166 & $27-37$ \\
\hline INR & $1.2(1.0-1.8)$ & $1(1.0-1.1)$ & 0.328 & $1.3(1.1-1.6)$ & $1.1(1.0-1.1)$ & 0.092 & $0.89-1.11$ \\
\hline Fibrinogen, mg/dl & $251.8(70-429)$ & $314.0(270-349)$ & 0.98 & $206.8(131-247)$ & $299.3(190-491)$ & 0.429 & $210-400$ \\
\hline
\end{tabular}

${ }^{a}$ Values are given as means (range). None of the parameters showed statistically significant differences between both groups. Nevertheless, note a distinct trend towards a more intense correction of conventional laboratory parameters in the control group.

Table 2. ROTEM parameters before $\mathrm{CPB}$, before weaning from $\mathrm{CPB}$, and at the end of surgery before admission at ICU in the ROTEM group ${ }^{\mathrm{a}}$

Table 3. Outcome parameters $^{\mathrm{a}}$

\begin{tabular}{lclcc}
\hline & Before heparin & $\begin{array}{l}\text { Before weaning } \\
\text { from CPB }\end{array}$ & End of surgery & Normal range \\
\hline CT EXTEM, s & $80.6(47-132)$ & $125.2(49-273)$ & $61.4(40-72)$ & $38-79$ \\
CT INTEM, $\mathrm{s}$ & $251.8(126-560)$ & - & $208.8(183-240)$ & $100-240$ \\
CT HEP TEM, s & $187.2(116-269)$ & $279.8(211-359)$ & $222.8(180-257)$ & $100-240$ \\
MCF EXTEM, mm & $56.2(42-68)$ & $41.0(22-61)$ & $58.6(56-65)$ & $50-72$ \\
MCF FIB TEM, mm & $13.4(0-26)$ & $8.6(0-20)$ & $19.6(19-26)$ & $9-25$ \\
\hline
\end{tabular}

${ }^{a}$ Values are given as mean (range). Values out of normal range are marked in italic digits. Note that goal-directed therapy after weaning from CPB resulted in ROTEM parameters within normal range at the end of surgery with avoidance of overtreatment.

\begin{tabular}{llll}
\hline & ROTEM group & Control group & $\begin{array}{l}\text { Two-sided } p \text { value } \\
\text { (Fisher's exact test) }\end{array}$ \\
\hline Massive transfusion ( $\geq 10$ units RBC transfused during surgery) & $0 / 5(0 \%)$ & $2 / 5(40 \%)$ & 0.444 \\
Massive transfusion ( $\geq 10$ units RBC transfused during surgery & $2 / 5(40 \%)$ & $4 / 5(80 \%)$ & 0.524 \\
$\quad$ and within the first $24 \mathrm{~h}$ at ICU) & $0 / 5(0 \%)$ & $1 / 5(20 \%)$ & 1.000 \\
Re-exploration because of bleeding & $0 / 5(0 \%)$ & $3 / 5(60 \%)$ & 0.167 \\
Thrombotic/thromboembolic adverse events & $0 / 5(0 \%)$ & $4 / 5(80 \%)$ & 0.048 \\
Composite bleeding and thrombotic/ thromboembolic adverse & & & \\
$\quad$ events & $0 / 5(0 \%)$ & $0 / 5(0 \%)$ & 1.000 \\
In-hospital mortality & $0 / 5(0 \%)$ & $2 / 5(40 \%)$ & 0.444 \\
6-month mortality &
\end{tabular}

${ }^{a}$ Values are given as numbers (\%). Only the difference in the incidence of composite bleeding and thrombotic/ thromboembolic adverse events achieved statistical significance (two-tailed p-value in the Fisher's exact test). One patient in the control group developed a cardiac tamponade requiring re-exploration, and in 3 patients in the control group thrombotic/thromboembolic adverse events could be detected (one cerebral infarction, one pulmonary embolism, and one embolism of the brachial artery used for cannulation for intraoperative isolated head perfusion). However, all other outcome parameters show the same distinct trend towards a better outcome in the ROTEM group, too.
$\mathrm{CG} ; \mathrm{p}=0.088)$, and PCs $\left(1.2 \pm 1.6 \times 10^{3} \mathrm{IU}\right.$ in RG vs. $3.6 \pm 0.5$ $\times 10^{3} \mathrm{IU}$ in $\left.\mathrm{CG} ; \mathrm{p}=0.070\right)$. Administration of antithrombin concentrate was significantly lower in RG $(0 \pm 0$ IU in RG vs. $3.2 \pm 0.8 \times 10^{3}$ IU in $\left.\mathrm{CG} ; \mathrm{p}=0.001\right)$ since its application was completely avoided during surgery in this group.

Within the first 24 postoperative $\mathrm{h}$ after admission at ICU (fig. 3), a significant reduction of FFP was detected in $\mathrm{RG}$
$(1.6 \pm 2.2$ units in RG vs. $9.2 \pm 6.6$ units in $\mathrm{CG} ; \mathrm{p}=0.04)$. During the whole study period (during surgery and the first 24 postoperative h at ICU) (fig. 4), the requirements for FFP $(6.2 \pm 2.0$ units in RG vs. $17.4 \pm 7.2$ units in $\mathrm{CG}$; $\mathrm{p}=0.039)$ and antithrombin concentrate $\left(0.2 \pm 0.4 \times 10^{3} \mathrm{IU}\right.$ in RG vs. $3.4 \pm 0.5 \times 10^{3}$ IU in $\left.\mathrm{CG} ; \mathrm{p}=0.001\right)$ were significantly reduced in RG. A nonsignificant reduction was detected for 


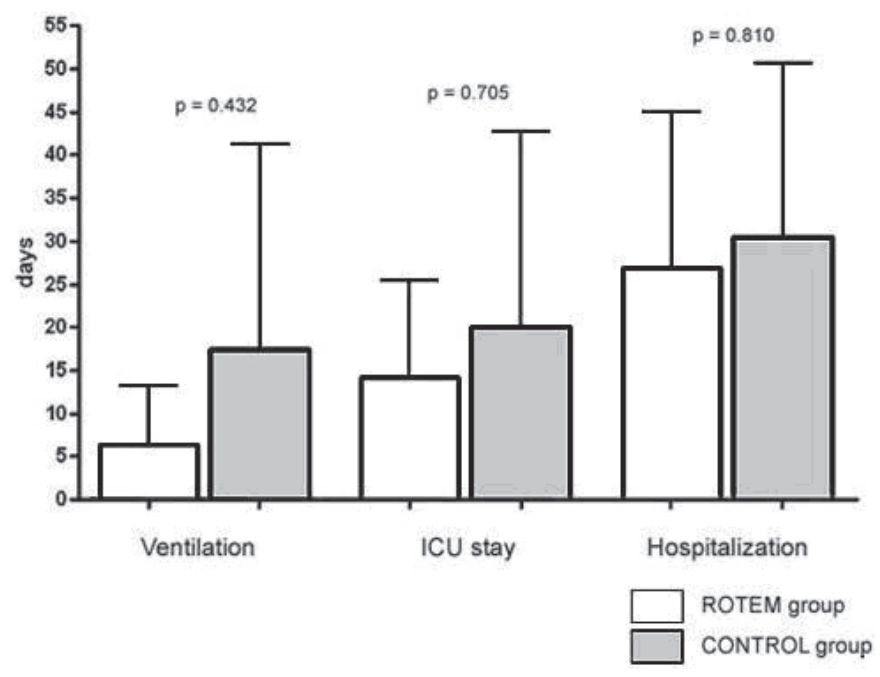

Fig. 5. Postoperative ventilation time, duration of stay at ICU, and hospitalization time. All parameters showed a trend to reduction in the ROTEM group (white bars) without achieving statistically significance. $\mathrm{ICU}=$ intensive care unit.

RBCs $(8.6 \pm 3.6$ units in RG vs. $13.2 \pm 4.5$ units in $\mathrm{CG}$; $\mathrm{p}=$ $0.178)$ and PCs $\left(1.6 \pm 1.5 \times 10^{3} \mathrm{IU}\right.$ in RG vs. $3.8 \pm 0.8 \times 10^{3}$ IU in CG; $p=0.075)$.

Conventional laboratory parameters are depicted in table 1. At ICU admission after surgery, hemoglobin levels and platelet counts were similar in both groups. aPTT was similar in both groups, too. A nonsignificant trend was found to lower INR and higher fibrinogen levels in CG .

ROTEM parameters before CPB, before weaning from $\mathrm{CPB}$, and at the end of surgery before admission at ICU are depicted in table 2 for ROTEM group only.

Outcome parameters are depicted in table 3. Incidence of composite bleeding and thrombotic/thromboembolic adverse events was significantly reduced in RG, showing no thrombotic/thromboembolic adverse events or bleeding complications requiring re-exploration. One patient in the CG developed a cardiac tamponade requiring re-exploration, and in 3 patients in the $\mathrm{CG}$ thrombotic/thromboembolic adverse events could be detected by computed tomography angiography: one cerebral infarction, one pulmonary embolism, and one embolism of the brachial artery used for cannulation for intraoperative isolated head perfusion. The incidence of intraoperative massive transfusion ( 210 units RBCs transfused during surgery), the incidence of massive transfusion during the whole study period ( $\geq 10$ units RBCs transfused during surgery and within the first $24 \mathrm{~h}$ at ICU) as well as the 6-month mortality were nonsignificantly reduced in the RG.

The postoperative course (fig. 5) showed nonsignificant trends in reduction of postoperative ventilation time, duration of stay at ICU, and hospitalization time in the RG, too.

Primary costs of transfused allogeneic blood components and administered coagulation factor concentrates tended to be less in the RG during surgery $(\mathrm{p}=0.086)$ and during the

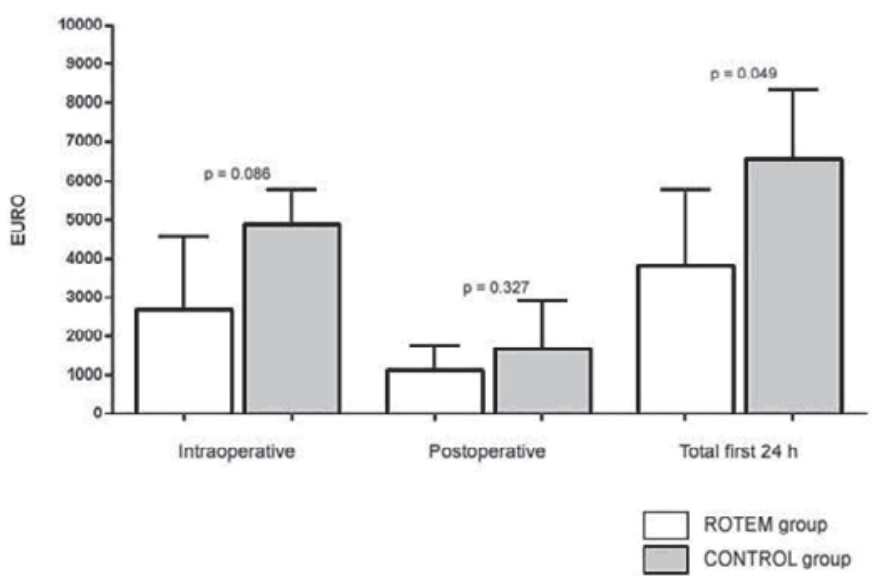

Fig. 6. Primary costs of transfused allogeneic blood products and coagulation factor concentrates per case: Primary costs of intra- and postoperative transfusion of allogeneic blood products and administered coagulation factor concentrates per case were reduced in the ROTEM group (white bars). Only reduction of overall costs (sum of intra- and postoperative costs) achieved statistically significance in this pilot study $(\mathrm{p}=0.049)$.

first $24 \mathrm{~h}$ at ICU $(\mathrm{p}=0.327)$, but reached statistical significance only for the whole study period $(\mathrm{p}=0.049)$ with an average costs-saving of EUR 2,757.00 per case (fig. 6).

\section{Discussion}

ROTEM as a point-of-care device enables early goal-directed therapy of bleeding disorders [13-24]. In this pilot study we found a promising trend towards reduction of transfusion requirements of allogeneic blood products and coagulation factor concentrates during aortic arch replacement and the postoperative period by using ROTEM-based point-of-care coagulation management. Accordingly, associated costs for allogeneic blood transfusion and coagulation factor concentrate administration decreased as well. Furthermore, postoperative ventilation time, duration of stay at ICU, hospitalization time, and 6-month mortality seemed to be reduced, but did not achieve statistical significance most likely due to the small number of patients in this pilot study. Reduced incidence of massive transfusion as well as absence of thrombotic/thromboembolic and bleeding incidents in the RG indicates a well calculated and balanced treatment of hemostatic disorders in the RG, whereas there seems to be a risk of overtreatment by using coagulation factor concentrates without point-of-care coagulation monitoring in the $\mathrm{CG}$.

Of note, beside reduced requirements for packed RBCs and FFP, administration of coagulation factor concentrates was not increased but rather reduced, too. A reason for this observation may be that ROTEM offers the possibility to monitor hemostasis even during complete anticoagulation during CPB by adding heparin inhibitors or heparinase into the test system. Conventional laboratory tests such as aPTT, 
PT, INR, or ACT cannot differ between heparin effects and prolonged clotting times due to a lack of fibrinogen or enzymatic coagulation factors or platelet dysfunction. Therefore, ROTEM enables a more sophisticated treatment of hemostatic disorders and seems to reduce transfusion requirements in major aortic surgery when compared to a 'blind' treatment. This blindness might result in an overtreatment with allogeneic blood products and coagulation factor concentrates in cases of massive bleeding. This again, may increase the risk of thrombotic/thromboembolic adverse events [26-27]. Furthermore, ROTEM analysis allow for early identification of the hemostatic defect even before heparin reversal with protamine. Therefore, the anesthetist can prepare for diffuse bleeding after weaning from CPB and for adequate administration of hemostatic drugs and coagulation factor concentrates in order to stop diffuse bleeding quickly after heparin reversal with protamine.

In the RG no adverse events were observed while in the CG 4 out of 5 patients showed thrombotic/thromboembolic or bleeding complications. In view of these complications the hemostatic status after surgery probably is of great importance. While there were no differences in conventional laboratory results at admission at ICU in regard to hemoglobin levels or platelet count, coagulation factor activity seemed to be at a higher level in the CG. Fibrinogen levels were within the normal range, and INR was considerably lower in the CG compared to the RG. This might be due to an uncontrolled use of procoagulant drugs in the CG in presence of severe bleeding after weaning from $\mathrm{CPB}$ without the possibility of prior detection of specific hemostatic defects and subsequent calculated goal-directed therapy. However, a calculated goal-directed therapy with effective hemostatic drugs and coagulation factor concentrates is only possible on the basis of point-of-care testing. This results in a well-balanced postoperative coagulation status at ICU admission, which seems to result in a reduced risk of bleeding and thrombotic/thromboembolic incidents as well. McCrath and coworkers [26] and Kashuk and coworkers [27] reported a good correlation between elevated maximum amplitude at the end of surgery and postoperative thrombotic complications and myocardial infarction. A wellbalanced coagulation system may account for the absence of these adverse events in the RG.

Transfusion practice based on point-of-care coagulation analysis has been shown to be associated with a significant reduction of transfusion requirements for RBCs, FFP and PCs without influencing median blood loss as compared to a transfusion regime based solely on the clinician's experience before [28]. However, in our pilot study using a point-of-care coagulation management algorithm based on ROTEM was associated not only with a significant reduction in transfusion requirements for allogeneic blood products but also with a decreased incidence of massive transfusion, composite bleeding and thrombotic/thromboembolic adverse events, and 6-month mortality. Accordingly, our data suggest that early, calculated, goal-directed therapy with hemostatic drugs and coagulation factor concentrates seem to be superior to a 'blind' therapy.

Of course, there are several limitations of our pilot study. First, this study was not prospective randomized, and blinded to the anesthetist in the operating room, and a standardized protocol in the CG is missing. It has been shown that the implementation of any algorithm or standard operating procedure (SOP) has the potential to reduce transfusion requirements compared to an unstructured approach [28]. Thus, it remains unclear if or to what degree the introduction of a standardized protocol in RG affected our data in the presented pilot study as compared to unstructured transfusion in CG. Second, the number of patients included in this pilot study was too small to allow final conclusions. Therefore, this study only reflects our first impression on ROTEM-based point-of-care coagulation management in patients with acute type A aortic dissection. Accordingly, based on results of this pilot study a prospective randomized trial powered for a significant reduction in transfusion requirements and improved outcomes is planned. Based on the presented pilot data, the effect size for $\mathrm{RBC}$ reduction (during surgery and the first $24 \mathrm{~h}$ at ICU) would be 1.1. A power analysis for a prospective randomized study would suggest a total sample size of 98 when carefully assuming an effect size of $0.8, \mathrm{p}<0.01$, and a power of 0.9 (G*Power 3.1, Franz Paul, University of Kiel, Germany).

In summary, our data suggest that ROTEM-based coagulation management can reduce transfusion requirements, corresponding adverse events, and costs, and thus can improve outcome in patients with acute type A aortic dissection. These data have to be confirmed by prospective randomized trials.

\section{Disclosure Statement}

$\mathrm{AH}, \mathrm{KG}$ and DD held lectures for CSL Behring and Tem International $\mathrm{GmbH}$.

\section{References}

1 Apaydin AZ, Islamoglu F, Posacioglu H, Calkavur T, Yagdi T, Atay Y, Buket S: Surgical treatment of acute arch dissection. Jpn J Thorac Cardiovasc Surg 2003;51:48-52.
2 Ghavidel AA, Tabatabaei MB, Yousefnia MA, Omrani GR, Givtaj N, Raesi K: Mortality and morbidity after aortic root replacement: 10-year experience. Asian Cardiovasc Thorac Ann 2006;14:462-466.
3 Irarrazaval Ll MJ, Moran VS, Zalaquett SR, Becker RP, Baeza PC, Urzúa UJ, Lema FG, Canessa BR, Chamorro SG, Braun JS, Córdova AS, Garayar PB: Partial or total replacement of the aortic arch. Experience in 23 patients. Rev Med Chil 2006;134:575-580. 
4 Khalil A, Tarik T, Porembka DT: Aortic pathology: Aortic trauma, debris, dissection, and aneurysm. Crit Care Med 2007;35(8 suppl):S392-400.

$>5$ Schachner T, Vertacnik K, Nagiller J, Laufer G, Bonatti J: Factors associated with mortality and long time survival in patients undergoing modified Bentall operations. J Cardiovasc Surg (Torino) 2005;46:449-455.

6 Yekeler I, Ates A, Ozyazicioglu A, Balci AY, Erkut B, Erol MK: Time and risk analysis for acute type A aortic dissection surgery performed by hypothermic circulatory arrest, cerebral perfusion, and open distal aortic anastomosis. Heart Surg Forum 2005;8:E337-E347.

7. Banbury MK, Brizzio ME, Rajeswaran J, Lytle BW, Blackstone EH: Transfusion increases the risk of postoperative infection after cardiovascular surgery. J Am Coll Surg 2006;202:131-138.

-8 Dara SI, Rana R, Afessa B, Moore B, Gajic O Fresh frozen plasma transfusion in critically ill medical patients with coagulopathy. Crit Care Med 2005;33:2667-2671.

$\checkmark 9$ Marik PE, Corwin HL: Efficacy of red blood cell transfusion in the critically ill: a systematic review of the literature. Crit Care Med 2008;36:2667-2674.

10 Murphy GJ, Reeves BC, Rogers CA, Rizvi SIA Culliford L, Angelini GD: Increased mortality, postoperative morbidity, and cost after red blood cell transfusion in patients having cardiac surgery. Circulation 2007; 116:2544-2452.

-11 Khan H, Belsher J, Yilmaz M, Afessa B, Winters JL, Moore SB, Hubmayr RD, Gajic O: Fresh frozen plasma and platelet transfusions are associated with development of acute lung injury in critically ill medical patients. Chest 2007;131:1308-1314.

12 Sarani B, Dunkman J, Dean L, Sonnad S, Rohrbach J, Gracias VH: Transfusion of fresh frozen plasma in critically ill surgical patients is associated with an increased risk of infection. Crit Care Med 2008;36:1114-1118.
13 Görlinger K, Jambor C, Hanke A, Adamzik M, Hartmann M, Rahe-Meyer N: Perioperative coagulation management and control of platelet transfusion by point-of-care platelet function analysis. Transfus Med Hemother 2007;34:396-411.

14 Görlinger K, Jambor C, Hanke A, Adamzik M, Hartmann M, Rahe-Meyer N: Thrombelastometry and impedance aggregometry based algorithm for coagulation management in cardiac surgery. Applied Cardiopulmon Pathophysiol 2007;11:42-43.

15 Görlinger K, Dirkmann D, Hanke AA, Kamler M, Kottenberg E, Thielmann M, Jakob H, Peters J: First-line therapy with coagulation factor concentrates combined with point-of-care coagulation testing is associated with decreased allogeneic blood transfusion in cardiovascular surgery. Anesthesiology 2011;115:1179-1791.

16 Dirkmann D, Görlinger K, Dusse F, Kottenberg E, Peters J: Early clot firmness predicts maximum clot firmness in thromboelastometry during cardiac surgery. Eur J Anaesth 2010;27(suppl 47):105-106.

17 Görlinger K: Gerinnungsmanagement bei Lebertransplantationen. Hämostaseologie 2006;26(suppl 1):S64-S76.

18 Görlinger K, Dirkmann D, Hanke A, Dusse F, Hartmann M: ROTEM-based algorithm for pointof-care coagulation management in visceral surgery and liver transplantation: experience of eight years and 829 LTX. Liver Transplant 2008;14(suppl 1):S203-204.

19 Görlinger K, Dirkmann D, Weber CF, RaheMeyer N, Hanke AA: Algorithms for transfusion and coagulation management in massive haemorrhage. Anästh Intensivmed 2011;52:145-159.

20 Lang T, Bauters A, Braun SL, Pötzsch B, von Pape KW, Kolde HJ, Lakner M: Multi-centre investigation on reference ranges for ROTEM thromboelastometry. Blood Coagul Fibrinolysis 2005;16:301-310.

21 Lang T, von Depka M: Diagnostische Möglichkeiten und Grenzen der Thrombelastometrie/-graphie. Hämostaseologie 2006;26(suppl 1):S20-S29.
Rahe-Meyer N, Solomon C, Winterhalter M, Piepenbrock S, Tanaka K, Haverich A, Pichlmaier M: Thromboelastometry- guided administration of fibrinogen concentrate for the treatment of excessive intraoperative bleeding in thoracoabdominal aortic aneurysm surgery. J Thorac Cardiovasc Surg 2009;138:694-702.

23 Reinhöfer M, Brauer M, Franke U, Barz D, Marx $\mathrm{G}$, Lösche W: The value of rotation thromboelastometry to monitor disturbed perioperative haemostasis and bleeding risk in patients with cardiopulmonary bypass. Blood Coagul $\mathrm{F}$ ibrinolysis 2008;19:212-219.

24 Solomon C, Pichlmaier U, Schoechl H, Hagl C, Raymondos K, Scheinichen D, Koppert W, RaheMeyer N: Recovery of fibrinogen after administration of fibrinogen concentrate to patients with severe bleeding after cardiopulmonary bypass surgery. Br J Anaesth 2010;104:555-562.

25 Herold U, Tsagaki K, Kamler M, Massoudy P, Assenmacher E, Eggebrecht H, Buck T, Jakob H: Paradigmenwechsel in der Chirurgie der komplexen thorakalen Aortenerkrankung. Herz 2006;31:434 442.

26 McCrath DJ, Cerboni E, Frumento RJ, Hirsh AL, Bennett-Guerrero E: Thromboelastography maximum amplitude predicts postoperative thrombotic complications including myocardial infarction. Anesth Analg 2005;100:1576-1583.

27 Kashuk JL, Moore EE, Sabel A, Barnett C, Haenel J, Le T, Pezold M, Lawrence J, Biffl WL, Cothren CC, Johnson JL: Rapid thrombelastography ( $\mathrm{r}$ TEG) identifies hypercoagulability and predicts thromboembolic events in surgical patients. Surgery 2009;146:764-772.

28 Avidan MS, Alcock EL, Da Fonseca J, Ponte J, Desai JB, Despotis GJ, Hunt BJ: Comparison of structured use of routine laboratory tests or nearpatient assessment with clinical judgement in the management of bleeding after cardiac surgery. Br J Anaesth 2004:92:178-186. 